\title{
ANÁLISIS DE LA INTERMEDIACIÓN FINANCIERA EN EL ESCENARIO DE LAS CRISIS DE LOS SIGLOS XX Y XXI
}

\section{ANAL YSIS OF THE FINANCIAL INTERMADIATION ON THE STAGE OF THE XX AND XXI CENTURIES CRISIS}

\author{
Carlos Mario García Díaz* \\ Giovanny Alexander Cárdenas Sánchez** \\ Carlos Hernando Molina Rodríguez ${ }^{* *}$
}

\author{
García D. Carlos M., Cárdenas S. Giovanny A., Molina R. Carlos H. Sophia Nº 7 - 2011. ISSN: 194-8932 Págs. 106-128. \\ Recepción: Junio 13 de 2011 \\ Aceptación: Julio 30 de 2011

\section{RESUMEN}

Este documento tiene como propósito el estudio del concepto de intermediación financiera y la contextualización del mismo en el entorno de algunas de las crisis financieras de los siglos XX y XXI.

En la primera parte se presenta un breve marco teórico de la intermediación financiera, desde el punto de vista de la asimetría de la información, la innovación financiera y la gestión del riesgo; e igualmente se expone el concepto de margen de intermediación.

En una segunda parte se describen algunas de las principales crisis financieras dadas en los siglos XX y XXI, tanto nacionales como internacionales, con el propósito de analizar el desempeño de la intermediación financiera durante su desarrollo. También se establecen relaciones y grado de influencia entre las políticas financieras y el comportamiento de los intermediarios.

\section{PALABRAS CLAVE}

Intermediación financiera, asimetría de la información, selección adversa, duplicación de screening, riesgo moral, margen de intermediación, represión financiera, crisis bancaria, tasa activa.

\section{ABSTRACT}

Ithis document is intended to study the concept of financial intermediation and the background of the same in the environment of some financial crisis made during the $X X$ and $X X I$ centuries.

* Ingeniero Financiero Universidad Piloto de Colombia, Licenciado en Matemáticas de la Universidad Distrital Francisco José de Caldas. Magister en Economía de la Universidad Javeriana. garciadiaz.carlosmario@gmail.com - Colombia.

** Semillero de Investigación ARISTOS del Programa de Ingeniería Financiera de la Universidad Piloto de Colombia. caarmol@ yahoo.com, Giovanny.cardenas@gmail.com - Carrera 9 No. 45A-44 Bogotá, Colombia. 
The first part presents a brief theoretical framework of financial intermediation, from the point of view of asymmetric information, financial innovation and risk management; and also explains the concept of financial intermediation margin.

The second part describes some of the major financial crises given in the $X X$ and $X X I$ centuries, national and international, in order to analyze the performance of financial intermediation during development. It also establishes relations and influence degree between the financial policies and the behaviour of intermediaries.

\section{KEY WORDS}

Financial intermediation, information asymmetry, adverse selection, duplicated screening, moral hazard, intermediation margin, financial repression, bank crisis, activate rate.

\section{INTRODUCCIÓN}

Historicamente siempre han existido agentes deficitarios y superavitarios, quienes desean intercambiar necesidades y recursos, pero este fin les resulta difícil de alcanzar, en forma directa, debido a que existen (1) problemas de asimetría de la información al transar, (2) riesgos asociados con el intercambio, y (3) diferencias en las solicitudes.

Por lo tanto, se hace indispensable la presencia de un sistema financiero que regule este tipo de actividades y que provea agentes económicos que intermedien entre las partes, contribuyendo en la atenuación de los problemas de asimetría de información, minimización de los riesgos y relación adecuada entre recursos y necesidades.
La eficiencia de las actividades del sector financiero es medida de acuerdo a la profundización del mercado y a la facilidad con la que los usuarios puedan acceder a servicios financieros, este acceso depende en gran parte de la interacción entre las tasas de captación y colocación, denominada margen de intermediación, y demás factores que inciden sobre este margen, tales como los costos de intermediación, los riesgos del mercado financiero, la competencia de otros intermediarios, la política fiscal, y el entorno institucional y regulatorio en el que se desenvuelve la actividad financiera.

Así que, éste trabajo tiene como propósito el estudio de la intermediación financiera y los factores que la determinan, e igualmente el análisis de la relación entre la intermediación y los principales componentes de las crisis financieras de los siglos XX y XXI.

\section{Mapa conceptual 1.}

Intermediación financiera: conceptualización y contextualización

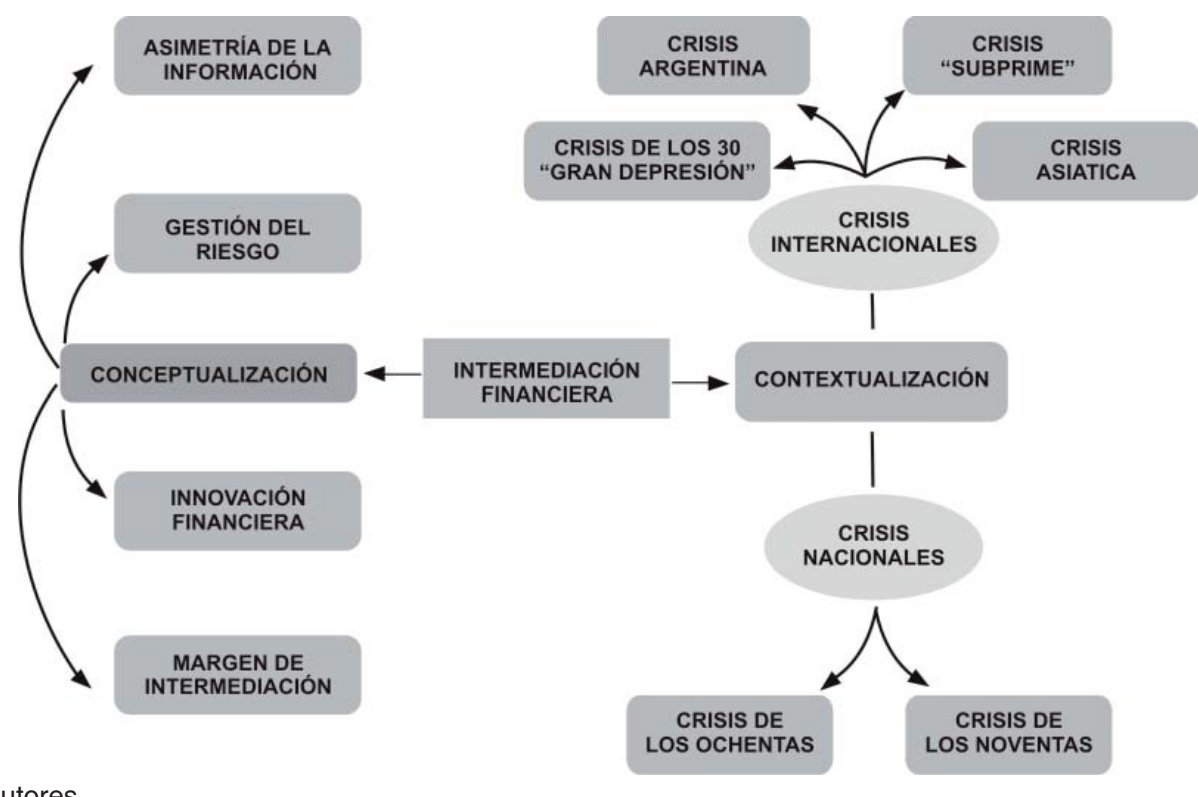

Diseñado por los autores. 


\section{INTERMEDIACIÓN FINANCIERA}

La razón por la cual existe la intermediación financiera, se debe a que en las transacciones financieras se evidencia asimetría de la información, la cual consiste en que una de las partes no demuestra suficiente esfuerzo, o no ofrece la información o garantías necesarias, en pro de preservar los intereses de la otra, y es por esto, que personas y compañías no se sentirían seguras si transarán servicios o activos financieros de manera directa. Dicha intermediación es realizada por agentes económicos que actúan como intermediarios entre proveedores y usuarios de capital financiero, los cuales brindan un mayor grado de seguridad sobre el cumplimiento de estas transacciones, basados en información que producen.

\begin{abstract}
"La información que generan los intermediarios financieros (en adelante IFs) es utilizada en dos tipos de aplicaciones: (1) para relacionar transacciones financieras, asociando recursos y necesidades, entre diversos agentes, y (2) para gestionar los riesgos y transformar la naturaleza de las demandas financieras, como cuando un banco produce información de carácter crediticia para controlar el riesgo de crédito de un prestatario. En el primer caso los IFs actúan como brokers, y en el segundo caso, como transformadores de las cualidades financieras de los activos. Estas aplicaciones son parte fundamental de la intermediación financiera". 1
\end{abstract}

Cuando los IFs actúan como brokers, además de relacionar, entre sí, las demandas y ofertas financieras de diferentes agentes económicos, también analizan e interpretan información, en busca de señales que le permitan tomar una buena decisión, en cuanto a comprar, vender o mantener su posición en productos del mercado financiero, o en cuanto a seleccionar un agente determinado en el cual invertir, en el caso de otorgamiento de créditos y financiamiento de proyectos; contribuyendo de esta manera en la solución del problema de asimetría de la información. Esta función les permite (a los IFs) desarrollar habilidades en el análisis de información, que no poseen demandantes y oferentes.

1 Traducción del autor. S. Greenbaum and A. Thakor. Contemporary Financial Intermediation. Second Edition. Pág. 42-43.
Dentro de este problema de asimetría de la información, se encuentra la selección adversa, la duplicación de screening y el riesgo moral.

La selección adversa es un problema precontrato, entendido como una selección equivoca de clientes o productos en la consolidación de una operación financiera, la cual es resultado de una valoración positiva con respecto al conjunto de información asociada, pero que posteriormente resulta no ser cierta, debido a falsedad u omisión en la misma. Este problema se presenta porque clientes y productos desean ser seleccionados, y por ello, se muestran como candidatos atractivos, pero ciertamente no cuentan con los requerimientos necesarios. Por tanto, es responsabilidad de los IFs desarrollar estrategias de valuación de información con el fin de determinar la calidad de los clientes y productos, minimizando así, el problema de selección adversa.

La duplicación de screening es igualmente un problema precontrato, el cual se evidencia cuando se presenta repetición del proceso de extracción de información, con fines financieros, sobre un mismo agente económico; esta duplicación se debe a que el agente aplicador de screening desconoce la ya existencia de dicha información o tiene limitaciones de acceso a la misma. Por tanto, como competencia de los IFs se encuentra la construcción de sistemas dinámicos de información que permitan la reutilización del conjunto de datos en diferentes solicitudes de carácter financiero, que involucran a un mismo agente económico o que comparten semejanzas en su objetivo, evitando, de esta manera, la duplicación de screening, y por ende, reduciendo costos de operación.

El papel de los IFs para contribuir en la solución de problemas de selección adversa y de duplicación de screening se hace más relevante, cuando el objeto de estudio no es fácilmente observable, hecho que los obliga a (IFs) mejorar la capacidad de observación de la información, en cuanto a completitud, especificidad e inferencia, ya que es, este nivel de capacidad, el que les permitirá distinguirse de su competencia.

El riesgo moral es un problema postcontrato, que se caracteriza porque: (1) el nivel de esfuerzo realizado por el agente (una de las partes en un 
contrato) no es verificable, hecho que puede afectar el resultado final de una operación en el caso que el agente no esté interesado en preservar los intereses del principal (la otra de las partes del contrato, que en nuestro estudio está representada por los IFs), o (2) el nivel de esfuerzo realizado por el agente es verificable, pero éste cuenta con información privada, después de firmado el contrato, que puede utilizar en detrimento de los interés del principal; en ambos casos la causa puede responder a que los intereses del agente difieren en gran medida de los del principal, por tanto, un bajo nivel de esfuerzo, o el uso de información privada, por parte del agente, no perjudicaría su nivel de utilidad, pero si afectaría la del principal, generándose asimetría en la información. Por ende, es tarea de los IFs atenuar posibles pérdidas, producto del riesgo moral, a partir de estrategias de seguimiento, tales como el monitoreo de los compromisos contractuales; el diseño de contratos ajustables, donde los agentes se sientan incentivados a cumplir, ya que sus intereses no divergen significativamente de los intereses del principal; entre otras.

Cuando los IFs actúan como transformadores de las cualidades o atributos financieros de los activos (tales como liquidez, duración, riesgo, divisibilidad), sus principales objetivos son los de generar economías de escala en las operaciones financieras, diversificar adecuadamente los riesgos y permitir un grado de ajuste, en monedas y plazos, pertinente entre activos y pasivos.

Más allá del uso y la aplicación, la intermediación financiera comprende el diseño de nuevos productos, servicios e instrumentos financieros, de financiamiento e inversión, y el diseño de metodologías para la gestión del riesgo, los cuales generan procesos de intermediación más especializados; como por ejemplo: (1) la cobertura del riesgo en una posición de mercado a partir de instrumentos denominados "derivados financieros", tales como swaps de divisas, swaps de tasas de interés, y contratos de opciones y futuros sobre acciones, commodities, divisas e índices; y (2) la construcción de modelos para la diversificación de portafolios de inversión, los cuales incorporan una estructura matemática de mayor robustez y la aplicación de nuevas teorías que se corresponden con la compleja dinámica de los mercados financieros.
"Esto ha conllevado (paralelamente) a que las actividades de las instituciones tradicionales, tales como bancos y compañías de seguros, cambien. Los bancos, los cuales acostumbraban tomar depósitos y otorgar préstamos, encontraron, por ejemplo, en la titularización de activos una posibilidad de diversificación, que les significaba que no era necesario mantener en sus balances todos los préstamos que pudieran originar. Al mismo tiempo, las compañías de seguros se dieron cuenta de que su función actuarial no era más que una pequeña parte de sus capacidades de gestión de activos, por tanto, también innovaron y ampliaron sus productos y servicios. También, otros IFs, como fondos mutuos y fondos de pensiones aumentaron su participación en los mercados financieros de capital y deuda" ${ }^{2}$, ofreciendo así, mayores oportunidades de diversificación y gestión del riesgo en portafolios de inversión.

\section{Margen de intermediación financiera}

Un elemento importante en la intermediación financiera, en particular, es el margen de intermediación $\left(M_{i f}\right)$, el cual se define como el resultado de la diferencia de intereses obtenidos por el volumen de colocaciones $(C)$ y los intereses pagados por el volumen de depósitos $(D)$, así:

$$
M_{i f}=\left[C^{*}{ }_{a}\right]-\left[D^{*} i_{p}\right]
$$

Una diferencia amplia entre la tasa activa $\left(i_{a}\right)$ y la tasa pasiva $\left(i_{p}\right)$, usadas en el cálculo del margen de intermediación (las cuales se explicarán más adelante), puede incentivar o desestimular la colocación y la captación de recursos económicos. Un elevado margen es indicador del nivel de ineficiencia de un sistema financiero, los cuales pueden estar siendo utilizados para protección del riesgo, cubrimiento de los costos de intermediación o para el fortalecimiento del capital de los IFs.

Entre los principales determinantes del margen de intermediación financiera están:

\section{A. Control de las tasas de interés ${ }^{3}$}

La tasa de interés es el precio del dinero en el mercado financiero; y al igual que el precio de

\footnotetext{
2 Traducción del autor. F. Allen and A. Santomero. The Theory of Financial Intermadiation. The Wharton Financial Institutions Center. 1996.

3 Banco de la República | ¿Qué es la tasa de interés?
} 
cualquier producto, cuando hay más dinero la tasa baja y cuando hay escasez sube. Cuando la tasa de interés ${ }^{4}$ sube, los demandantes desean comprar menos, es decir, solicitan menos recursos en préstamo a los IFs, mientras que los oferentes buscan colocar más recursos. Lo contrario sucede cuando la tasa baja, los demandantes del mercado financiero desean solicitar más créditos, y los oferentes retirar sus depósitos.

Existen dos tipos de tasas de interés: la tasa pasiva o de captación, es la que pagan los IFs a los oferentes de recursos por el dinero captado; y la tasa activa o de colocación, es la que reciben los IFs de los demandantes por los préstamos otorgados. Esta última siempre es mayor, porque la diferencia con la tasa de captación es la que permite a los IFs cubrir los costos administrativos, dejando además una utilidad para ellos. La diferencia entre la tasa activa y la pasiva se conoce también como margen de intermediación.

\section{B. Impuestos}

Cuando el margen de intermediación es afectado por elementos impositivos (impuestos) se da lo que se denomina el efecto pass through, donde se traslada de manera total o parcial los costos del impuesto hacia el precio de los recursos financieros. Cuando se traslada de manera parcial repercute en una reducción de la rentabilidad de los IFs, lo que puede generar una restricción al crédito, y por ende, una desviación de recursos hacia otro tipo de inversiones más rentables, cuando este traslado se da de manera total, limita la demanda de los usuarios por los recursos financieros.

Existen dos categorías de impuestos que afectan la actividad de intermediación, se definen como: "Explícitos, si generan un recaudo fiscal para el gobierno, o implícitos, si no implican un costo tributario sobre la intermediación, pero la afectan negativamente, (Demirguc y Huizinga 1999; Cardoso 2003 y Honohan 2003)" 5.

4 La tasa de interés también tiene asociado un riesgo, referente a la disminución del valor de los activos o del patrimonio de una entidad debido a las variaciones en las tasas. Riesgo bancario. Biblioteca virtual del Banco de la República.

5 Citado en Martínez Constanza. Revista ESPE № 48. Junio 2005. Pág. 121.
Los impuestos explícitos, pueden ser directos e indirectos, entre los más comunes se encuentran los impuestos sobre las rentas y los impuestos a las operaciones financieras. Los impuestos implícitos se caracterizan por no constituir tributación directa; son cargas que debe asumir el sistema y que generan efectos similares a los generados por los impuestos explícitos sobre la intermediación; algunos de estos son el encaje bancario, las inversiones forzosas, los créditos dirigidos a sectores específicos, los techos a las tasas de interés, entre otros (Demirguc y Huizinga, 2000).

La aplicación de estos impuestos sobre las actividades que desarrollan los IFs genera efectos en los precios de los activos, influyendo generalmente de forma negativa en las decisiones de los agentes económicos. Por lo tanto, la imposición de estas medidas tributarias debe ser óptima y no debe desincentivar la demanda por servicios financieros, ni afectar la rentabilidad del sistema, por lo contrario, deben causar la menor distorsión en el mercado, teniendo en cuenta siempre el objeto principal de funcionamiento del sector.

\section{Encaje bancario ${ }^{6}$}

Debido a que la intermediación financiera es una actividad de gran responsabilidad, puesto que en este negocio se involucran los ahorros del público y los recursos que se tienen establecidos con algún propósito, los cuales no se pueden poner en riesgo por parte de estas instituciones, el Banco Central establece una cantidad mínima de dinero que las instituciones financieras deben mantener permanentemente, la cual no pueden utilizar para otras actividades, lo que garantiza que éstas puedan retornar a los ahorradores en caso de que ellos lo soliciten, o en el caso que se presenten problemas de dinero al interior de dichas instituciones financieras. De esta forma, se disminuye el riesgo de pérdida de dinero de los ahorradores.

El encaje bancario, lo establece el Banco Central y corresponde a un porcentaje del total de los depósitos que reciben las instituciones financieras, porcentaje que han de guardar, ya sea en efectivo en sus cajas o en sus cuentas en el Banco Central. El encaje bancario también es utilizado por el Banco Central para regular la cantidad de dinero que

6 Texto basado en el documento del Banco de la República
| ¿Qué es el encaje bancario? 
circula en la economía. Si el Banco considera que el dinero circulante en la economía es demasiado, éste puede aumentar el porcentaje del encaje bancario, de manera que las instituciones financieras no puedan prestar todo el dinero que tienen, ya que deben mantener una parte en reservas, así la cantidad de dinero que circula en la economía disminuye. Sucede lo contrario cuando el Banco Central baja el porcentaje de los encajes, ya que las entidades financieras tienen más recursos para prestar y, por consiguiente, la cantidad de dinero circulante en la economía aumenta.

Aunque el Banco Central pueda utilizar la herramienta del encaje para aumentar o disminuir la cantidad de dinero circulante en la economía, el verdadero propósito del encaje es el de garantizar a los depositantes y ahorradores la posibilidad de retirar sus recursos en caso de que lo soliciten.

\section{Inversiones forzosas y crédito dirigido}

Representa un costo de oportunidad para los bancos, el cual se ve reflejado en el margen de intermediación, este se calcula como un porcentaje de inversiones obligatorias sustitutivas del encaje dentro de los depósitos. Este porcentaje de depósitos debe ser invertido en determinados títulos con bajos rendimientos o en forma de créditos a bajo costo en sectores específicos considerados por los gobiernos como prioritarios.

\section{CRISIS FINANCIERAS INTERNACIONALES}

Ahora, se pretende analizar el desempeño de la intermediación financiera dentro del desarrollo de algunas crisis financieras que datan de los siglos $\mathrm{XX}$ y XXI, e igualmente establecer relaciones, y grado de influencia, entre las políticas financieras impuestas por gobiernos, bancos centrales e instituciones de control y supervisión, y el comportamiento de los IFs.

\section{A. La gran depresión 1930}

\section{a) Antecedentes, causas y consecuencias}

En la década de los 20, los consumidores y las empresas utilizaban créditos baratos para comprar bienes de consumo, y los empresarios, a su vez, invertían más capital para aumentar la producción, pero debido al desequilibrio que existía en la distribución de la riqueza entre la clase alta y la clase media, entre la industria y la agricultura, y entre la economía mundial y los Estados Unidos, no se logró generar una demanda suficiente que pudiese sustentar dicha expansión industrial. Por tanto, durante el periodo de 1925 a 1927 fue creciendo un problema de sobreproducción, que influyó para que los empresarios se interesaran por la inversión en negocios especulativos.

La compra de acciones en la bolsa se convirtió en uno de los negocios especulativos más rentables. Los empresarios pedían créditos a los bancos, respaldados por las acciones que compraban, ya que la ganancia de las mismas podía llegar a un $50 \%$ anual y el interés que debían pagar por los créditos bancarios era del $12 \%$, obteniendo así, grandes beneficios. A finales de la década, la prosperidad, que antes estaba basada en el desarrollo industrial, pasó a depender de la especulación.

A pesar de la sobreproducción de mercancías, que no podían ser vendidas, y el despido masivo de trabajadores, que llevaron a que el crecimiento de las empresas se detuviera, el valor de las acciones de la bolsa seguía creciendo debido a una gran demanda de los especuladores, lo que no reflejaba la situación económica real. Cuando en octubre de 1929 la Bolsa de Nueva York quebró, la crisis fue inevitable y se extendió al sistema bancario a la industria, al comercio y al agro, estadounidenses. El jueves 24 de octubre de 1929, se produjo el Crash de la Bolsa de Wall Street, donde más de 13.000 .000 de títulos que cotizaban en baja no encontraron compradores y ocasionaron la ruina de miles de inversores, muchos de los cuales, habían comprado las acciones con créditos que ya no podrían pagar al sistema bancario.

Esto llevó a que la gente entrara en pánico, y quienes poseían dinero en cuentas bancarias corrieron a retirarlo. Los bancos no tuvieron la capacidad para responder a la gran cantidad de retiros, esto debido también a que en los Estados Unidos se había tratado de hacer frente al descenso de la demanda con una expansión del crédito a los sectores más comunes, lo que terminó de desbordar a los bancos, quienes estaban llenos de créditos que ya no podían ser pagados por sus clientes. Ante esto, se negaron a dar nuevos créditos y a refinanciar las deudas existentes, pero 
sin embargo, más de 1.000 bancos americanos quebraron.

La gran depresión de 1930 fue una de las mayores crisis económicas en la historia de Estados Unidos, la cual también afectó a los países industrializados, Ilevando a la economía mundial a un escenario de inestabilidad financiera. Entre los factores que desencadenaron la crisis están: especulación exagerada, desigualdad de riqueza, dependencia económica mundial con respecto a la economía norteamericana, devaluación de las monedas, debilitamiento del sistema financiero internacional y disminución en las exportaciones.

\section{b) La intermediación financiera en la depresión de 1930}

Los bancos que habían financiado la deuda comenzaron a tener problemas de morosidad, y al cundir el pánico, los depositantes empezaron a retirar sus depósitos masivamente, provocando múltiples quiebras bancarias. Las garantías del gobierno y las regulaciones bancarias de la Reserva Federal para prevenir el pánico fueron ineficaces. Las quiebras bancarias provocaron la pérdida de millardos de dólares en activos. Las deudas pendientes de pago se convirtieron en enormes, porque los precios y los ingresos disminuyeron entre un $20-50 \%$, pero las deudas se mantuvieron en el mismo monto en dólares.

A partir de esta situación, de préstamos incobrables y el empeoramiento de las perspectivas de futuro, los bancos sobrevivientes se hicieron aún más conservadores en sus préstamos, acumulaban reservas de capital y concedían menos préstamos, lo que intensificó la presión deflacionista. En parte este proceso pudo haber sido el responsable de convertir la recesión de 1929 en una gran depresión.

La estructura bancaria, estaba formada por múltiples y pequeños bancos, cuya supervivencia financiera dependía del alza de los valores bursátiles, ya que un gran porcentaje de los créditos estaba en manos de inversionistas especulativos en la bolsa de valores. De esta forma el negocio de los bancos era prestar a corto plazo a un interés del 12 por ciento, ya que ellos obtenían créditos de la Reserva Federal al 5 por ciento. Por lo tanto, su margen de inter- mediación era bueno, pero dependían mucho de la especulación bursátil y contribuían al alza de los valores.

La dependencia generada por los bancos hacia la operación bursátil, produjo con el Crash de 1929 el hundimiento y debilitamiento del sistema bancario, la evidencia es la quiebra entre 1929 y 1932 de más de 1.000 bancos en EEUU (como se mencionó en las consecuencias); además de otros en Alemania, Austria y Gran Bretaña, lo que a su vez produjo restricciones en el crédito.

Por otro lado, tras la crisis y el fracaso de la administración del presidente Herbert C. Hoover (1929-1933), los demócratas ganan las elecciones con Franklin D. Roosevelt (1933-1945) quien siempre creyó, que un sistema bancario basado en la especulación era perjudicial para el Sistema de la Reserva Federal, por lo tanto, implantó una política para reactivar el consumo y la inversión denominado el "New Deal" de la cual hacía parte la Ley Glass-Steagall; entre las características más importantes esta Ley Bancaria están:

- La total separación de la actividad bancaria de la bursátil.

- Se creó un sistema bancario conformado por bancos nacionales, bancos estatales y bancos locales.

- Para evitar una competencia desleal entre estos, se aplicó la Ley Anti-monopolio de Teodoro Roosevelt, que permitía sólo un 18 por ciento de control por cada institución financiera nacional, estatal o local.

- Los bancos fueron vetados de participar en los manejos de los fondos de pensiones.

- Se prohibió a los bancos participar en los consejos de administración de las empresas industriales, comerciales y de servicios.

- Se prohibió a los bancos suscribir acciones conjuntas con otras empresas y participar directamente en el mercado bursátil.

- Sólo el 18 por ciento de los ingresos del banco podía provenir del mercado bursátil, y solo a través de casas de bolsa que no estuvieran bajo su control.

- Se creó una comisión de vigilancia, autónoma, la SEC (Securities and Exchange Commission), autorizada a aplicar san- 
ciones a los bancos y casas de bolsa que especularan con los recursos del público.

En general, esta ley contribuyo con el fortalecimiento de la estructura del sistema financiero, y en particular, en el direccionamiento de las actividades de los IFs, que a su vez se reflejaba, en disminución de riesgos tanto para el público depositante, como también en riesgos que los Bancos tomaban en los mercados bursátiles y de dinero. Por otro lado, elimino los conflictos de interés entre los accionistas de empresas y banqueros, que pactaban dinero a muy bajo interés, generando competencia desleal para el resto del sistema económico de libre mercado, la idea era no permitir una Banca Universal ó Múltiple que abarcará un sinnúmero de actividades.

En conclusión, dentro de la Gran Depresión de 1930, se evidencian problemas de gestión del riesgo de mercado, en cuanto a no prever las funestas consecuencias que se derivarían de un alto nivel de especulación; también problemas de asimetría de la información basados en una débil estructura de asignación y monitoreo de créditos, y en la consolidación de préstamos respaldados con garantías de alta volatilidad, además de un escaso control sobre éstos por parte del Estado; igualmente se identifican altos márgenes de intermediación financiera, hecho que incentivo la oferta de créditos sin la debida rigurosidad, que posteriormente se transformó en una fuerte restricción de liquidez.

\section{B: Crisis asiática ${ }^{7}$}

\section{a) Antecedentes, causas y consecuencias} Desde 1990, Asia comenzó un proceso de liberalización financiera ${ }^{8}$, caracterizado por la desregulación del sistema financiero, dejando de establecer mecanismos necesarios de regulación y supervisión. Algunos puntos de este proceso son:

(1) la eliminación de las barreras de entrada de la intermediación financiera, que promovió el

7 Esta crisis incluye a los países de Corea del Sur, Filipinas, Indonesia, Malasia, Tailandia, Taiwán, Singapur y Hong Kong.

8 Disminuir la intervención del gobierno en el sistema financiero, así como sus efectos distorsivos. ingreso de nuevas instituciones no bancarias, pero sin experiencia en el mercado.

(2) mayor margen en las decisiones de endeudamiento y préstamo de las instituciones financieras, y eliminación de las restricciones a la financiación de la deuda de las empresas, que conllevo a un crecimiento del crédito bancario ${ }^{9}$ hacia el sector privado.

(3) la apertura de la cuenta de capital y la desaparición, casi total, de las limitaciones a los empréstitos ${ }^{10}$ internacionales, lo que condujo a una menor evaluación de la calidad de los préstamos concedidos, una mayor exposición al riesgo de tipos de interés y de cambio, y un creciente endeudamiento ${ }^{11}$ a corto plazo en moneda extranjera, utilizado para financiar préstamos a largo plazo en moneda nacional, que originaba a su vez un mayor desequilibrio en la composición, en cuanto a monedas y plazos, entre deuda y activos.

Los préstamos bancarios internos se dirigieron principalmente a las bolsas de valores y al mercado inmobiliario, ya que los préstamos para el consumo y la inversión no resultaban rentables, dada las altas tasas de ahorro privado y la caída en la rentabilidad de las inversiones manufactureras.

Las economías asiáticas asombraban al mundo por su rápido crecimiento económico y desarrollo tecnológico, su entorno e indicadores macroeconómicos durante el periodo 1990-1996 eran favorables: bajos déficit presupuestarios, limitada deuda pública, inflación moderada, altas tasas de ahorro e inversión, crecimiento del PIB, elevadas entradas de capital extranjero, bajas tasas de desempleo y unos elevados índices de ahorro respecto del PIB, por ejemplo en éste último, Corea 35\%, Malasia $41 \%$, y Singapur $50 \%$. Es así como, las crisis financieras asiáticas fueron totalmente imprevistas.

9 También contribuyó a este aumento el hecho de que obtener fondos en moneda extranjera a corto plazo para invertir en actividades locales a largo plazo era muy rentable.

10 Empréstitos: Operación financiera que realiza el Estado o los entes públicos, normalmente mediante la emisión de títulos de crédito, para atender sus necesidades u obligaciones.

11 Estimaciones del Banco de Pagos Internacionales (BPI) indican que los empréstitos interbancarios internacionales, en países que posteriormente estaban en crisis, ascendían anualmente a alrededor de 43.000 millones de dólares, de lo cual aproximadamente el 40 por ciento estaba en yenes y el resto en dólares. 
El sudeste asiático sufrió, en términos generales, una crisis de balanza de pagos ${ }^{12}$, pero con diferencias importantes entre los distintos países del área, con la excepción particular de Corea del Sur, donde inicialmente no se presentó un elevado déficit corriente, tan sólo problemas de liquidez en bancos y empresas, aunque tiempo después, aparecieron los problemas de solvencia internacional.

Los movimientos de la liquidez mundial también se reflejaron en los márgenes de los instrumentos de deuda de los mercados emergentes, que se redujeron significativamente a principios de 1995. Fue en el último trimestre de 1997, después de iniciada la crisis, que los márgenes de la deuda de los mercados emergentes se ampliaron, de casi 13 puntos porcentuales durante junio de 1997 a 37,5 en enero de 1998, pero retrocediendo moderadamente en los meses siguientes. Esa volatilidad de los márgenes demuestran las dificultades que tuvieron los mercados financieros con el riesgo de las tasas de interés.

\section{b) La intermediación financiera en la crisis asiática}

El origen de la crisis asiática corresponde a un bajo desempeño de la intermediación financiera, es decir, como se introdujo en las causas, esta crisis se deriva de un excesivo crecimiento del crédito y de un elevado nivel de confianza sobre fondos de capitales demasiado volátiles; además de un exagerado aumento de la inversión en algunos sectores, el cual tendió a disminuir la tasa de rentabilidad de nuevos capitales.

El alto grado de estabilidad de las monedas asiáticas y sus tipos de cambio, junto con un rápido desarrollo de los sistemas bancarios locales, facilitaron un largo período de crecimiento dirigido a la inversión, pero posteriormente, la excesiva expansión del crédito bancario (gráfica 1) generó una capacidad industrial no rentable, ciclos de alta volatilidad en los precios de los activos accionarios, y niveles de deflación que deprimieron la demanda de productos, incluidos los valores accionarios, hecho que dejó a los bancos con préstamos incobrables.

12 Una crisis de balanza de pagos se origina por la insostenibilidad de una moneda apreciada en un contexto de alto déficit por cuenta corriente.
Gráfica 1 Comportamiento del crédito en Asia (1985-1996, créditos reales 1985=100)

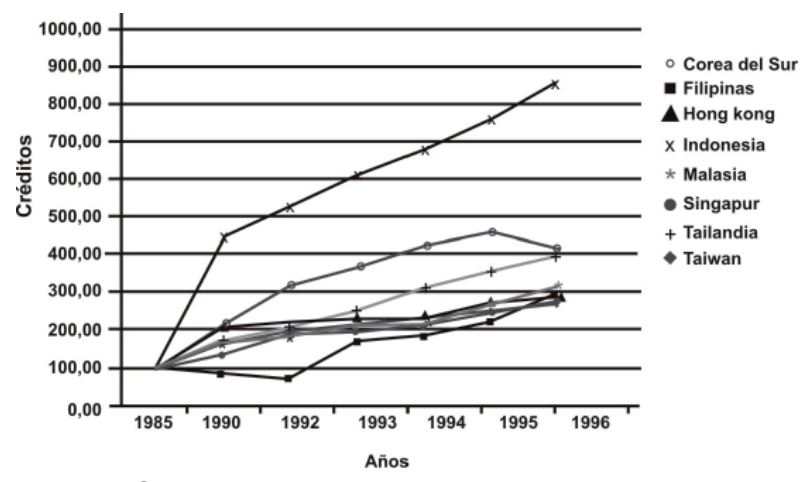

Fuente: CEPAL

También, la apertura a la cuenta de capital (mencionado en las causas) generó un incremento de la inversión extranjera, atraída por las altas tasas de interés internas; las empresas aumentaron su nivel de endeudamiento; $y$ el financiamiento externo fue canalizado principalmente en el sistema bancario interno, en especial, endeudamiento de corto plazo, que fue utilizado en el financiamiento de inversiones de largo plazo, en activos nacionales reales, tales como propiedades. De esta manera, las economías asiáticas se hicieron más vulnerables a la volatilidad de los mercados financieros internacionales.

La devaluación de sus monedas se hizo inminente, para lo cual, los países asiáticos, aplicaron la estrategia de elevar las tasas de interés a corto plazo para frenar el deterioro del tipo de cambio, reduciendo luego, las tasas de interés en forma gradual a medida que se estabilizara el tipo de cambio. El aumento inicial de las tasas de interés fue moderado y de corta duración: en Tailandia, las tasas de interés a corto plazo subieron al $25 \%$, y en Corea al $35 \%$, y se mantuvieron a esos niveles máximos sólo algunos días, para luego bajar rápidamente hasta los niveles previos a la crisis. Las tasas de interés reales (basadas en el pronóstico de consenso de la inflación como medida de las expectativas inflacionarias) que fluctuaban en torno al 7\%-8\% antes de la crisis, subieron durante un breve lapso al $20 \%-25 \%$, pero luego bajaron rápidamente. Al mismo tiempo, tanto el won como el baht se apreciaron considerablemente después de la crisis inicial. En cambio, en Indonesia, los intentos iníciales de estabilizar la rupia fracasaron; 
en la primera semana de ejecución del programa de Indonesia, las autoridades llevaron a cabo una intervención y permitieron que las tasas de interés a corto plazo subieran al doble (30\%); como resultado, la rupia registró una fuerte apreciación, pero dos días después, contrariando el acuerdo entre el país y el FMI, el Banco de Indonesia rebajó las tasas de interés hasta su nivel inicial, provocando una expansión de la liquidez, lo que precipitó la caída de la rupia, y generó altos niveles de inflación, hecho que exigió tasas de interés mucho más elevadas para recobrar la estabilidad financiera, proceso que implicó un alto costo.

La poca solidez de los sectores bancario y empresarial de los países de Asia limitaron las posibilidades de elevar las tasas de interés, por tanto, continuó la depreciación de sus monedas, que a su vez produjo efectos negativos en la estabilidad financiera de estos países, donde la proporción de la deuda externa era demasiado alta en relación con el crédito interno.

La contracción de la liquidez que se produjo en la crisis asiática, no solo fue consecuencia de las altas tasas de interés, sino también de la restricción y refinanciación del crédito por parte de los bancos, debido al alto volumen de préstamos en mora y a la situación del sector empresarial.

En conclusión, en las crisis asiáticas se evidencia un bajo desempeño en análisis de información, por parte de los IFs y de las instituciones de regulación, control y supervisión, ya que indicadores macroeconómicos no convencionales, tales como la tasa de inversión y de rentabilidad del capital, el cociente entre deuda externa a corto plazo y reservas en divisas, y el nivel del crédito bancario vinculado a la liberalización financiera, no fueron analizados con rigurosidad; también se hacen visibles problemas de gestión del riesgo asociado con el financiamiento hacia las empresas, debido a que no se logró prever las consecuencias que se derivarían por otorgar créditos hacia sectores que se encontraban dentro de mercados cada vez más saturados; e igualmente se identifican problemas de gestión del riesgo de tasa de interés y de tipo de cambio, los cuales se incrementaron debido a reformas en las políticas financieras relacionadas en la cuenta de capital y los empréstitos internacionales, esta ausencia de gestión se hace evidente en los desequilibrios de la balanza de pagos y en la composición entre deuda y activos.

\section{Crisis económico - financiera Argentina 2000}

\section{a) Antecedentes, causas y consecuencias}

En la década de los años noventa, Argentina, crecía a niveles cercanos a un 50\%, pero el gasto público crecía en un $90 \%$ (gráfica 2), por tanto, este crecimiento era insostenible dado el alto nivel de endeudamiento que se registraba en el país. El gobierno siempre mantuvo un creciente déficit fiscal, es decir, que el gasto público nunca paró de crecer; aunque algunas reformas realizadas por nuevos gobiernos, como el plan de convertibilidad $^{13}$, permitieron frenar la excesiva emisión monetaria que utilizaba el sector público como fuente de financiamiento, la cual condujo a la economía a un estado de de híper-inflación durante el periodo de 1983 - 1989 (346\% de media anual en $1983-1989 ; 1.344 \%$ en 1990 y $84 \%$ en 1991 ), de igual manera, el gasto público continúo creciendo por encima del PIB, pero paso a ser financiado a través de la venta masiva de activos estatales y la emisión de bonos de deuda.

\section{Gráfica 2}

Deuda pública República Argentina (1990-2001, US\$)

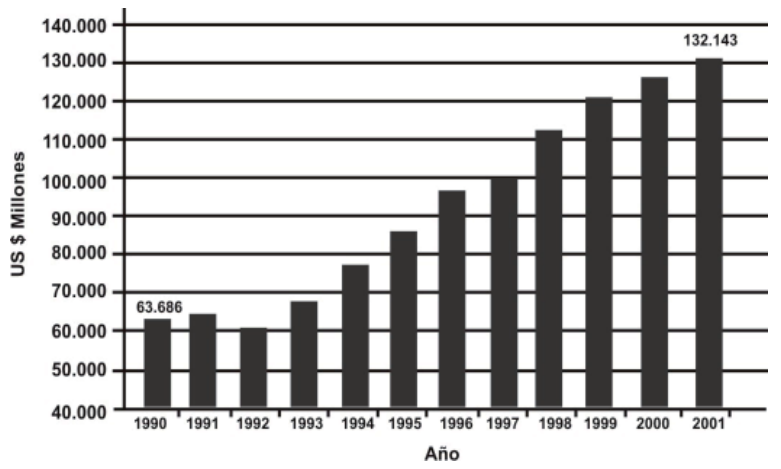

Fuente: Instituto ecuatoriano de economía política.

$13 \quad$ Plan de convertibilidad. Los siguientes 4 puntos se identificaron como el "plan de convertibilidad":

1) La implantación de un sistema de convertibilidad: el tenedor de moneda nacional tenía el derecho, si así lo deseaba, de comprar dólares, dado que esta era la moneda de conversión que se eligió. De esta manera, se planteaban dos cuestiones: (a) la moneda extranjera 
La crisis se inicia durante el segundo y tercer trimestres del año 2000; entre las causas se encuentran: (1) la dificultad para conseguir fondos, por parte del gobierno, (2) la falta de empresas estatales para vender, (3) el aumento de la tasa de desempleo, (4) la sobrevaluación del peso argentino, y (5) el alto costo de los créditos, debido al incremento de la tasa de interés interbancaria como consecuencia del elevado déficit fiscal, del aumento del riesgo país derivado de la caída de los precios de los bonos ya emitidos, y del aumento de la tasa de interés internacional para los nuevos créditos.

La deuda Argentina aumentó rápidamente debido a las alzas en las tasas de interés de la economía norteamericana, aunque también influyeron en el incremento de esta deuda las crisis de México, Rusia, Asia y Brasil; por ende, el riesgo país aumento y como consecuencia los nuevos créditos tomados por Argentina se hacían a tasas de interés bastante elevadas.

\section{b) La intermediación financiera en la crisis Argentina $^{14}$}

La regulación bancaria Argentina, vigente durante los años noventa, permitía la constitución de depósitos y créditos en moneda extranjera y facilitaba el acceso de las entidades financieras a los mercados de capitales internacionales, hecho que produjo una creciente dolarización de los depósitos y créditos bancarios (gráfica 3 ); esta misma regulación prohibía que se ofrecieran tasas de interés superiores por los depósitos denominados en pesos, respecto a los depósitos denominados en dólares; tam-

era propiedad de quien la poseía y (b) quién poseía moneda extranjera podía disponer de ella sin restricciones.

2) Bimonetarismo: se modificó el código civil para dejar establecido que las obligaciones podían ser abonadas y el deudor se liberaba de ellas pagando en cualquiera de las dos monedas que se establecieron con curso legal: el peso y el dólar.

3) Un tipo de cambio fijo entre las dos monedas que tenían curso legal, sostenido por el estado y establecido por ley.

4) Una regla de relación entre la magnitud de las reservas y el circulante. Esto dejaba al Estado sin posibilidad de incrementar la cantidad de dinero primario, independientemente de la razón.

14 Argentina, al igual que la mayoría de países de América Latina, tiene un sistema financiero basado más en IFs bancarios que en IFs del modo bursátil. poco se podía cobrar comisión alguna por la conversión de pesos a dólares, en ningún tipo de transacción. Aunque, durante este periodo, el sistema financiero reflejaba estabilidad financiera y cambiara, el cortoplacismo y la dolarización generaban algunas dudas sobre la sostenibilidad del sistema.

\section{Gráfica 3}

Depósitos y créditos en dólares (1991-2000, \%)

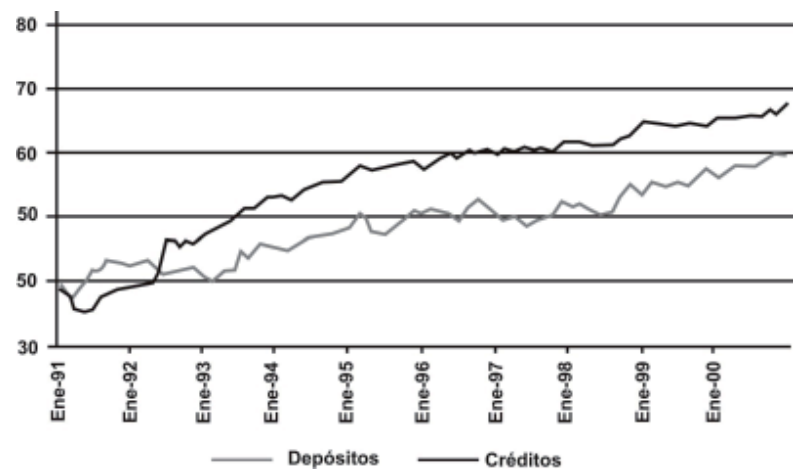

Fuente: Banco Central de la República de Argentina.

Esta creciente dolarización aumentó el riesgo de descalce de monedas, ya que un porcentaje significativo de la deuda en moneda extranjera fue utilizado para financiar bienes y servicios no comerciables, además tampoco se exigió, con relación a los IFs, la constitución de previsiones por el riesgo derivado al operar con moneda extranjera, bajo la forma de reservas o mayor capitalización. Así que, la deuda en divisas sobrepasó los ingresos en divisas para financiarla, además los bancos no tomaron coberturas para sus posiciones abiertas en moneda extranjera, ya que el gobierno se había comprometido a mantener un tipo de cambio fijo; convertibilidad que actuó como seguro de cambio gratuito durante algunos años.

Los incentivos pro dolarización de las regulaciones son causa importante en la crisis Argentina; el sistema terminó en crisis cuando el mercado fue plenamente consciente de que el Gobierno no estaría en condiciones de seguir financiando el subsidio que estaba otorgando, es decir, que el Gobierno no estaría en condiciones de endeudarse en el exterior para vender dólares baratos a los agentes domésticos. 
En el año 2000, los depósitos representaban cinco veces el patrimonio neto de las entidades, y el plazo residual del $80 \%$ de los pasivos bancarios totales no excedía los tres meses. Esta característica de los depósitos en términos de plazos pone en evidencia la preferencia por flexibilidad en las decisiones de cartera y el uso del plazo corto como un instrumento para acotar el riesgo moral, factor que hizo más vulnerable al sistema financiero.

Por otro lado, dados los problemas que tenía el Gobierno para financiarse a través de la emisión, éste recurrió al mercado financiero, en donde obtuvo los recursos que requería, pero a medida que la deuda crecía, el riesgo país se incrementaba y las posibilidades de nuevos préstamos disminuían; esto condujo a que el gobierno se financiará, posteriormente, en el mercado local llegando a asfixiar al sector privado, ya que absorbió gran parte del crédito disponible, generando efectos negativos en diversas ramas productivas ${ }^{15}$, disminución en su calificación de riesgo crediticio, y aumento de las tasas de interés; por tanto, los IFs se vieron obligados a aumentar sus márgenes de intermediación, durante el periodo 2000-2002 (gráfica 4), para tratar de subsanar las pérdidas.

\section{Gráfica 4}

Tasa activa y pasiva República Argentina (19992002, \%)

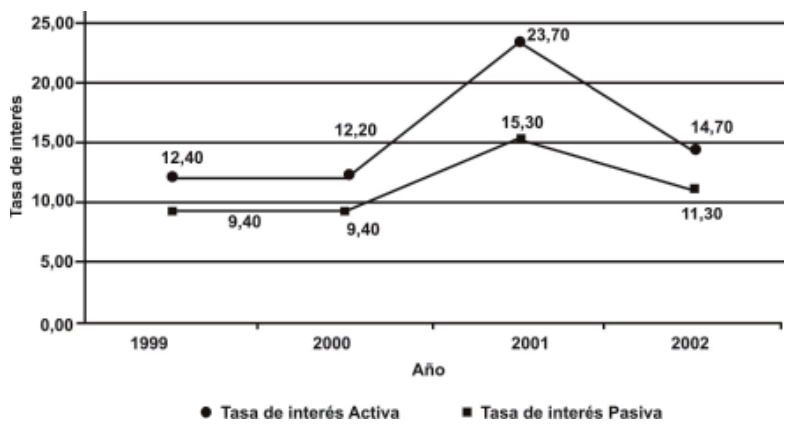

Fuente: CEPAL, SELA, Banco Mundial, FMI, BID.

15 De acuerdo a De Ampuero Dora. Crisis bancaria: causas y posibles soluciones (2005); las empresas argentinas competían contra empresas de todo el mundo, pero la desigualdad de condiciones respecto a crédito y tasa de interés y las regulaciones con respecto al mercado laboral hacían a la economía Argentina muy poco competitiva.
A partir de abril de 2001, el nivel de los depósitos caía drásticamente, debido a que los ahorradores percibieron que las posibilidades de sacar su dinero del banco disminuían; igualmente en septiembre de 2001 se sanciono la ley de intangibilidad de los depósitos ${ }^{16}$, con el fin de que retornará la confianza del público hacia el sistema financiero; que fue deteriorada en cierta medida por las actuaciones del Gobierno.

Argentina nunca dejó de pagar su deuda a los organismos multilaterales (Fondo Monetario y Banco Mundial), pero sí dejó de pagar su deuda a los acreedores privados, la mitad de la deuda en moratoria estaba en manos de argentinos, quienes fueron los perjudicados; igualmente los bancos no pudieron devolver los depósitos, lo que era un obstáculo para resolver la crisis bancaria. Las obligaciones sumaban en septiembre de 2002 alrededor de 12.000 millones de dólares.

Las consecuencias para el sistema financiero, fue la quiebra casi total y la desconfianza de los ahorradores hacia el sistema, ya que estos migraron hacia un banco off shore, y si bien el sistema financiero se fue recuperando en parte a las captaciones atraídas por altas rentabilidades a tasas fijas, aun la mayor parte del dinero de Argentina está fuera del país.

En conclusión, la crisis financiera en Argentina 2000-2001, ha sido explicada por algunos analistas como el resultado de la incompatibilidad entre el régimen cambiario (derivado de la junta monetaria creada en 1991) y la política fiscal (responsable del déficit presupuestario). En esta crisis se evidencia problemas de gestión del riesgo cambiario, que conllevaron a un descalce de monedas, además de que los bancos no cubrieron sus posiciones en moneda extranjera, ni tampoco constituyeron previsiones para proteger los depósitos de los ahorradores;

$16 \quad$ La cual consiste en que todos los depósitos, ya sean en pesos o en moneda extranjera, a plazo fijo y a la vista, captados por las entidades financieras, son considerados intangibles; dicha intangibilidad consiste en que el Estado nacional en ningún caso, podrá alterar las condiciones pactadas entre el/los depositantes y la entidad financiera esto significa la prohibición de canjear éstos, por títulos de la deuda pública nacional, u otro activo del Estado nacional, ni prorrogar el pago de los mismos, ni alterar las tasas pactadas, ni la moneda de origen, ni reestructurar los vencimientos, los que operarán en las fechas establecidas entre las partes. 
problemas de gestión del riesgo de contraparte, al proporcionar altos niveles de financiamiento hacia el Gobierno, basados seguramente en la hipótesis de que los Gobiernos no se quiebran, pero éste se encontraba seriamente endeudado; y también la adopción de medidas inadecuadas para atenuar el riesgo moral, como el uso del plazo corto en las financiaciones.

\section{Crisis subprime EE.UU}

\section{a) Antecedentes, causas y consecuencias} La crisis subprime se gestó durante un largo periodo de tiempo, caracterizado por altos niveles de consumo, y una alta liquidez proporcionada quizás por los países emergentes, ya que estos invertían grandes montos de capital en bonos del tesoro americano producto de las ventas de sus commodities a buenos precios. Esta crisis estuvo antecedida por los grandes problemas referidos a la burbuja de especulación del mercado inmobiliario durante el año 2006 en Estados Unidos, que posteriormente provocó en el tercer trimestre de 2007, la llamada "Crisis de las Hipotecas Subprime", seguida por una drástica caída en los precios de la vivienda.

Desde un inicio se creyó que esta crisis solo afectaría al mercado inmobiliario, pero no fue así, ésta traspaso rápidamente a otros sectores económicos y a otros países, trayendo como consecuencia graves problemas de liquidez, ya que las divisas que necesitaban para financiar su consumo eran insuficientes; en otras palabras, lo que vendían en el exterior no les alcanzaba para pagar lo que estaban comprando, de aquí, el efecto negativo en su balanza comercial y de pagos; esto a su vez, causó otros fenómenos económicos, tales como una crisis alimentaria global, diversos derrumbes bursátiles, y en conjunto, una crisis económica a escala internacional.

A finales del 2007, los mercados de valores de Estados Unidos comenzaron una precipitada caída que se acentuó en los inicios del 2008, en donde sobresalen los CDO's ${ }^{17}$, los cuales sufrieron un desplome masivo y drástico en sus precios, resultado de la baja calidad de sus colaterales, lo que disminuyó velozmente las expectativas

17 Hipotecas convertidas en bonos securitizados, los cuales han sido considerados como los detonantes de la crisis. del mercado; esta baja en el mercado se agudizó por alzas en el precio del petróleo, aumento de la inflación y estancamiento del crédito, factores que exageraron el pesimismo global sobre el futuro económico de EE.UU, hundiéndolo en una profunda recesión, que involucró aumento en el nivel de desempleo y del costo de vida, y quiebras en diferentes empresas y bancos. La gravedad llegó hasta el punto en que las decisiones de inversión y financiación por parte de los agentes bursátiles en la Bolsa de Valores respondían en gran medida a "rumores" financieros.

El estallido de la crisis financiera se da en el momento en que los Bancos Centrales tuvieron que intervenir para proveer de liquidez al mercado financiero, debido a la extrema incertidumbre que reinaba. Bancos de inversión de todo el mundo registraban grandes pérdidas, debido a que las empresas dejaron de comprar bonos por valor de miles de millones de dólares, debido a las precarias condiciones de inversión que se reflejaban en el mercado; por otro lado, también estaban las aseguradoras, las cuales perdieron credibilidad al no poder responder con las obligaciones que habían contraído en la securitización de estos títulos valores, acrecentando aún más los problemas de la crisis.

Cuando las economías de todo el mundo se vieron afectadas por los graves problemas de liquidez, que involucran la carencia de crédito, algunas comenzaron a nacionalizar bancos, como en el caso de Islandia y Francia, y en otras, los bancos centrales realizaron un significativo recorte sobre los tipos de interés, en un esfuerzo para alentar los préstamos, como en el caso de los EEUU donde la FED bajó su tipo de interés directriz ${ }^{18}$ pasando del $5 \%$ a principios de 2007 al 0,5\% a finales de 2008 (grafica 5), igualmente hubo recortes de tasas en Canadá y algunas partes de Europa. Sin embargo, a corto plazo, estas medidas no resolvieron la crisis de liquidez, ya que: (1) la desconfianza que se generó entre los bancos, quienes se financian tradicionalmente, tomando dinero prestado a corto plazo en el mercado interbancario, restringió el crédito entre ellos mismos, lo que llevo a un aumento de los tipos interbancarios, que inclusive

18 Tasa a la que la Reserva Federal presta a los bancos. También actúa como tasa de referencia de toda la estructura de tasas de interés. 
sobrepasó el tipo directriz del Banco Central, (2) el comportamiento de las acciones era demasiado volátil, estas subían y bajaban a causa de las noticias sobre fracasos, adquisiciones y rescates asociados con las medidas adoptadas, (3) el dólar estadounidense sufría un proceso constante de devaluación y el déficit comercial continuó creciendo abruptamente, la ventaja exportadora, por un dólar débil, fue completamente anulada en el intercambio comercial por el alza de los precios del petróleo, del cual EEUU importaba el $50 \%$, y (4) millones de familias perdían sus hogares, e instituciones como General Motors, Ford, Chrysler y muchas aerolíneas padecían serias dificultades financieras. Todo esto conllevó a que el índice de confianza del consumidor se situara en su nivel histórico más bajo.

\section{Gráfica 5}

Tasas de intervención en EE.UU (2003-2009, \%)

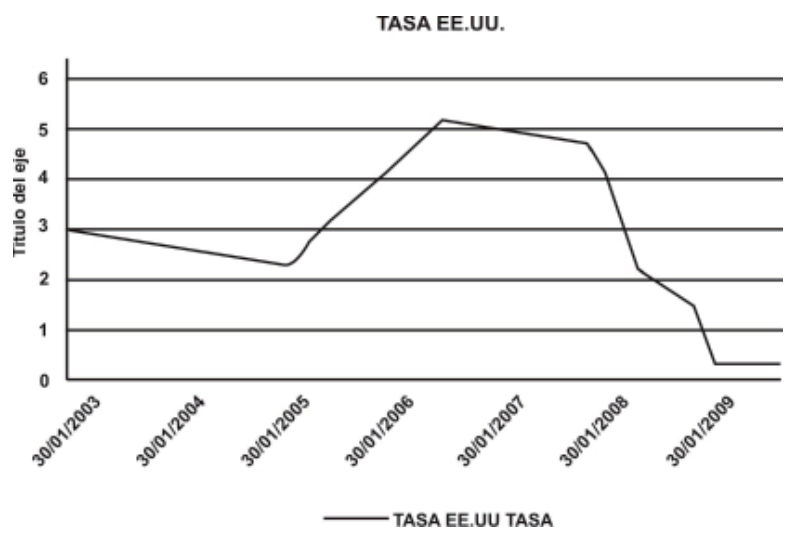

Fuente: INFOFINANCIERA

En sí, las medidas adoptadas por las autoridades económicas y financieras tales como: la inyección de liquidez desde los bancos centrales, la intervención y la nacionalización de bancos, la ampliación de la garantía de los depósitos, la creación de fondos millonarios para la compra de activos dañados - la garantía de la deuda bancaria, tenían como objetivo mantener la solvencia de las entidades financieras, restablecer la confianza entre las mismas entidades, atenuar las turbulencias bursátiles y hacer que los ahorradores se sintieran seguros de sus depósitos. Igualmente, la política monetaria adoptada durante la crisis, se caracterizó por una extensión de la duración de los préstamos, una ampliación de las garantías y la posibilidad de obtener refinanciación.

\section{b) La intermediación financiera en la crisis subprime}

Durante muchos años se quiso creer que un proceso continuo de innovación financiera, podría ser la base de la productividad y del progreso económico, y a partir de esta creencia, se permitieron e impulsaron todo tipo de prácticas de ingeniería financiera orientadas a modelar estrategias para generar nuevos recursos a partir del papel; prácticas muy exitosas desde el punto de vista de la rentabilidad pero acompañadas de un alto nivel de riesgo.

A partir del año 2001, la Reserva Federal inició un proceso de expansión monetaria y reducción de las tasas de interés para evitar una recesión en los EEUU. En los años previos se había desarrollado una gran especulación financiera con las acciones tecnológicas en medio del furor de lo que se denominaba la nueva era de la tecnología, basada en la evolución del Internet. Cuando el precio de las acciones tecnológicas se derrumbó, el gobierno norteamericano temía que esta caída bursátil pudiera arrastrar a la economía a una recesión, por tanto, la Reserva Federal redujo las tasas de interés de los fondos federales de manera rápida y gradual, y estas bajísimas tasas de interés llevaron a los bancos a desarrollar todo tipo de nuevas operatorias para compensar el menor margen de intermediación que se había derivado de esta decisión, igualmente, las nuevas políticas gubernamentales sobre oferta de créditos para la vivienda, decretadas en este tiempo, las cuales favorecían a sectores de la población que eran considerados vulnerables, condujeron a los bancos hacia el mercado de créditos hipotecarios.

El fuerte aumento en los préstamos hipotecarios en EE.UU, clasificados en tres categorías ${ }^{19}$ : prime, alta $A$ y subprime, suscitaron en cierta medida la crisis subprime, ya que los bancos quienes estaban empeñados en la búsqueda de mejores rentabilidades, comenzaron a financiar la totalidad del valor de la vivienda y aceptaron a personas cuyos ingresos no eran suficientes como para asegurar el repago de esas deudas, constituyendo así, una cartera de alto riesgo debido a que predominaban

19 Esta clasificación se basa en la calidad de los créditos, la cual depende de dos factores: (1) la relación entre monto del préstamo y el valor de la vivienda, y (2) la magnitud de los ingresos del deudor. 
los agentes económicos de categoría subprime; operatoria que se facilitó por las bajas tasas de interés, ya que con tasas tan bajas, las cuotas de los créditos parecían accesibles. De esta manera, se entró en un círculo aparentemente virtuoso, ya que la mayor oferta de créditos llevó a aumentar el valor de las propiedades y luego con estas propiedades más valiosas, los bancos estaban dispuestos a otorgar más y mayores créditos hipotecarios, ya que la garantía de esos préstamos (es decir, las viviendas) crecían en valor; pero este círculo no perduró, después de cierto tiempo estos inmuebles perdieron drásticamente valor en el mercado, hasta llegar al punto que la deuda de la hipoteca sobrepasaba el valor de la vivienda. Estos mismos bancos se prestaron para que otros IFs titularizaran su cartera de baja calidad, a partir de derivados financieros, comercializados en las bolsas de valores, los cuales permitían "trasladar" al mercado, los riesgos asociados con estos préstamos, evitando que se reflejaran negativamente en los balances de los bancos, pero finalmente esté traslado no se materializó de forma positiva. De esta manera, el proceso de innovación financiera y el relajamiento de las condiciones crediticias en el otorgamiento de préstamos para la vivienda, se convirtieron en los factores más relevantes del proceso de securitización ${ }^{20}$.

En palabras de González Iturriaga: "los bancos originaron los créditos, pero posteriormente los distribuyeron, así que no se quedaron en una relación de largo plazo con sus clientes, esto generó una secuencia, en la que los bancos trataban de crear y crear lo necesario para distribuir cada vez más, y cobrar el necesario fin; con esta actitud los bancos perdieron uno de sus roles esenciales, como lo es la capacidad de mantener una relación de largo plazo con sus clientes; por el contrario, se dedicaron a la construcción de paquetes de crédito para venderlos a otras instituciones financieras creadas a la par de la regulación". ${ }^{21}$

20 La securitización consiste en transformar activos de largo plazo y de difícil negociación, como los préstamos hipotecarios, en títulos fácilmente negociables en los mercados de valores.

21 Tomado de la conferencia del Dr. Claudio González Iturriaga denominada: Análisis de la Crisis Financiera Mundial derivada de las Hipotecas Subprime. II Seminario Internacional Mercados Competitivos. Programa de Ingeniería Financiera UPC. 2008.
En conclusión, en esta crisis se evidencia grandes problemas de asimetría de información, reflejados en el desconocimiento de algunos IFs, unos como emisores y otros como inversores, en cuanto a la estructura de composición de los paquetes de créditos titularizados, respaldados por las hipotecas subprime, y la forma de valoración de los mismos; como por ejemplo, el deficiente desempeño de las Agencias Calificadoras de Riesgo que otorgaron equívocamente buenas calificaciones de inversión a estos papeles, y el de las Compañías Aseguradoras quienes securitizaron los títulos valores basados en cálculos de siniestralidad incorrectos; dos acciones que facilitaron la expansión de estos instrumentos dentro del mercado financiero mundial. También hay problemas de asimetría de información derivados de la transferencia de responsabilidades en cuanto a la evaluación del riesgo de contraparte, que en cierta medida fue realizada por otras instituciones financieras y no por los bancos, quienes eran los directos responsables de los desembolsos, por ende, nunca debieron descuidar esta función, ya que esto produjo el crecimiento de cartera de baja calidad. Otro aspecto importante, tiene que ver con el marco regulatorio, el cual permitía la realización de operaciones complejas, basadas en el uso de ingeniería financiera, que se enfocaron en el cómo distribuir el riesgo de los créditos hipotecarios, sin una adecuada evaluación del riesgo asociado con los títulos valores creados para dicha distribución (los CDO's), riesgo que se infería alto desde un comienzo debido a los colaterales que soportaban estos títulos. Esta ineficiencia global, por parte de algunos IFs, llevó a que el Gobierno aplicará algunas medidas para atenuar la crisis subprime de manera directa sobre los consumidores, eludiendo a los IFs.

\section{INTERMEDIACIÓN FINANCIERA EN COLOMBIA}

Colombia, al igual que la mayoría de países de América Latina, tiene un sistema financiero basado más en IFs bancarios que en IFs del mercado bursátil, por tanto, en el análisis de la intermediación financiera en el escenario de las crisis nacionales se enfatiza principalmente en los bancos.

Una mirada histórica reciente de los márgenes de intermediación financiera en Colombia, muestra que estos han disminuido durante los últimos 20 años, debido a un comportamiento favorable de 
sus determinantes, a una mayor eficiencia del sistema financiero que ha venido aumentando continuamente desde los años noventa, a la liberalización financiera dada a principios de la misma década, y a una mayor competencia entre IFs. Sin embargo, de acuerdo a estudios del BID, los márgenes de intermediación colombianos siguen siendo elevados, lo que es común en la mayoría de países de América Latina, en promedio los márgenes de la región se ubicaron en el $8.5 \%$ entre 1995 y 2002, lo cual es superior a los registrados en Argentina, México, Chile y Perú, aunque inferiores a los de países como Venezuela, Jamaica, República Dominicana, Brasil y Paraguay, mientras que en los países desarrollados los márgenes de intermediación alcanzaron niveles del 3\%.

Por otra parte, en varios países de la región se emprendieron reformas dirigidas a liberar el sector financiero, que consistió en reducir los coeficientes de encaje, eliminar los controles a las tasas de interés, desmontar las inversiones forzosas y los créditos dirigidos hacia sectores productivos específicos. Sin embargo, después de quince años de las reformas financieras, países como Ecuador, y especialmente Colombia, siguen teniendo un alto grado de intervención del gobierno en la actividad financiera.

En Colombia la apertura y liberación de la economía a comienzos de los noventa, condujo a un proceso de reforma de la estructura y operación del sector financiero. Las medidas más importantes de esta reforma son:

- Simplificación del proceso de entrada y salida de entidades financieras.

- Adopción de un esquema multibanca.

- Reducción de cargas impositivas como el encaje bancario y las inversiones forzosas.

- Privatización de entidades.

- Se permitió que hasta el $100 \%$ del capital de un banco fuera de extranjeros.

El objetivo de estas reformas era principalmente que los márgenes de intermediación en Colombia disminuyeran y se acercaran a estándares internacionales. Algunos trabajos realizados al respecto, como el de Carrasquilla y Zarate (2002) ${ }^{22}$, mues-

22 Carrasquilla y Zarate. El Sector Financiero de Cara al Siglo XXI. Bogotá. ANIF 2002. Páginas: 215-230. Volumen 1. tran que la regulación para el sector financiero se redujo entre 1992 y 1998, y que se incremento a razón de la crisis financiera entre 1999 y $2002^{23}$, esto evidenciaba la tendencia pro cíclica en las cargas regulatorias hacia los IFs (gráfica 6). Por otro lado, trabajos como el de Barajas (1999), explican la relación positiva entre el margen de intermediación con la influencia de la tasa pasiva sobre la tasa activa, la tributación del sector financiero, la represión financiera ${ }^{24}$, el volumen de crédito, los costos laborales y el porcentaje de cartera vencida, además encuentra que la liberación financiera aportó un mayor grado de competencia entre los IFs, que a su vez se reflejó en una mayor eficiencia.

\section{Gráfica 6}

Índices de represión financiera y margen (19502002)

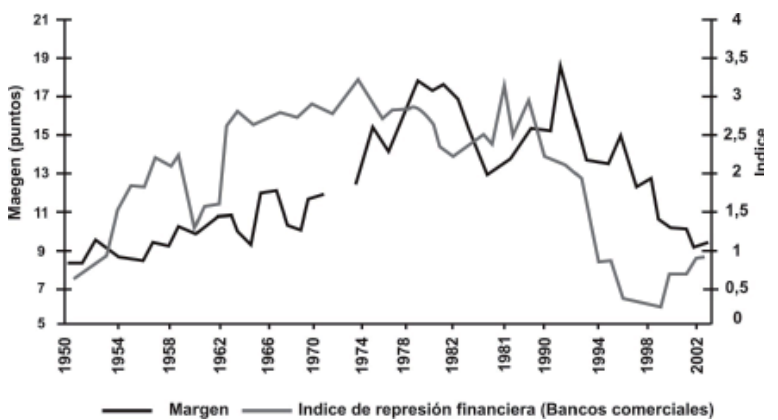

Fuente: INFOFINANCIERA

El nivel de competencia al interior de un determinado mercado está dado por el número de empresas (bancos) y el grado de concentración. En Colombia, entre 1991 y 1998, las entidades bancarias pasaron de 33 a 41 y el grado de concentración, medido con el índice de Herfindahl-hirschman ${ }^{25}$,

23 Igualmente, trabajos posteriores como el realizado por Villar, Salamanca y Murcia (2005) muestra que la represión financiera venía reduciéndose desde la segunda mitad de la década del setenta y confirma su incremento a partir de 1999 a raíz de la crisis financiera.

24 Intervención del Gobierno en la actividad financiera caracterizado por impuestos, controles en los niveles de tasa de interés, altos requerimientos de encajes bancarios, inversiones forzosas y crédito dirigido.

25 El índice herfindahl hirschman es una medida para estimar concentraciones de mercado, se obtiene al ajustar la cuota del mercado de cada empresa que compite. Puede extenderse de 0 a 10.000; menor de 100 (o menor de 0,01) indica un mercado altamente competitivo, entre 100 y 1000 
se redujo de 556 a 433 , lo que significa que el mercado era competitivo. Después de la crisis financiera de 1998-2000, se inició un proceso fuerte de fusiones y adquisiciones en el sistema bancario, que redujo el número de bancos, que para finales del 2004 era de 27 , lo que incremento el índice de Herfindahl-hirschman a 710, es decir, un mercado aunque de poca concentración, pero menos competitivo.

En cuanto al nivel de eficiencia del sector bancario colombiano, este se encuentra en un rango promedio entre el $30 \%$ y $70 \%$, siendo 100 la frontera de eficiencia; (Suescún y Misas 1996; Castro 2001; Badel 2002; Janna 2003; Estrada y Osorio 2003; y ANIF 2005).

En términos generales y de acuerdo al contexto económico y financiero de Colombia, durante la última mitad del siglo XXI, el comportamiento del margen de intermediación ha estado relacionado con los costos no financieros de la intermediación, la estructura del mercado, los impuestos, los riesgos mismos de la intermediación, y la inflación.

A continuación se describe brevemente el comportamiento de los principales componentes del margen de intermediación, en Colombia, durante las décadas que antecedieron y enmarcaron las crisis financieras nacionales de los 80 's y 90 's:

\section{En cuanto al control a las tasas de interés}

En Colombia, el control a las tasas de interés, consiste en la fijación de un piso correspondiente al interés bancario corriente y un techo el cual es 1.5 veces el interés bancario corriente para las tasas de interés cobradas por los bancos para los diferentes créditos. La tasa activa de los bancos estuvo controlada entre 1952 y 1974, en este último año fue liberada, y a partir de 1999, a raíz de la crisis hipotecaria, se volvió a controlar; mientras que la tasa pasiva estuvo controlada entre 1950 y 1981. En la actualidad el Banco de la República sigue fijando el mínimo y el máximo de las tasas de interés a las cuales pueden transar los IFs para captar y colocar recursos.

(o entre 0,01 y 0,1 ) indica un mercado poco concentrado, entre 1000 y 1800 (o entre 0,1 y 0,18 ) indica un mercado moderadamente concentrado, y mayor de 1800 (o mayor de 0,18 ) indica un mercado altamente concentrado.

\section{Gráfica 7}

Tasa activa y pasiva bancos comerciales (19502002, \%)

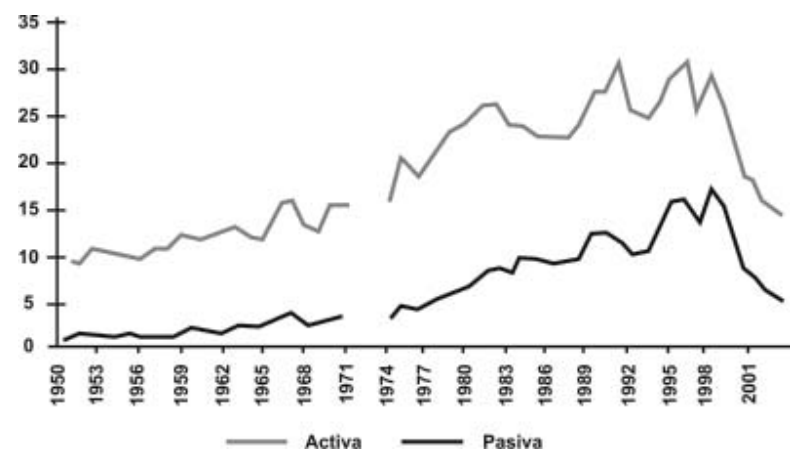

Fuente: : ANIF.

\section{En cuanto al encaje bancario}

Entre 1950 y 1970 el encaje bancario paso del $1 \%$ al $25 \%$, descendiendo a niveles del $15 \%$ hasta la primera mitad de la década del ochenta en donde se presentó una subida temporal como consecuencias de los efectos inflacionarios de la bonanza cafetera de 1986 hasta 1990 cuando se sitúo en el $22 \%$, luego descendido hasta cerca del $11 \%$ en 2003.

\section{En cuanto a inversiones forzosas y crédito dirigido}

En el caso de Colombia este porcentaje se ha mantenido alrededor del 14\% desde 1960 hasta 1985 año desde el cual ha presentado una disminución hasta llegar al 3\% en 1995, esto como efecto de la reforma financiera de 1990, la cual desmonto las inversiones forzosas, sin embargo como consecuencia de la crisis hipotecaria se reactivaron las inversiones en títulos de FINAGRO y los TDR, lo que evidenció un ascenso al $5 \%$ de inversiones forzosas en el año 2003; a pesar de la reducción del número de bancos en Colombia el nivel de concentración sigue siendo reducido. Aunque el grado de concentración no es siempre un determinante del nivel de competencia.

\section{En cuanto a la inflación}

Aunque la relación entre el margen de intermediación y la inflación no es tan evidente, hay dos canales a través de los cuales se puede afectar los costos de la intermediación financiera (Banco República, 2000); uno de ellos es cuando los ban- 
cos cumplen con los requerimientos de encajes, escenario en el que se ven expuestos a enfrentar el impuesto inflacionario, ya que en este caso la inflación perjudica negativamente la rentabilidad asociada con dichos montos; y un segundo canal se refiere a los riesgos financieros que gestionan los IFs en escenarios de inflación. En el grafico 8 se puede ver que existe una relación directa entre el margen de intermediación financiera y la inflación, durante un largo periodo de tiempo.

\section{Gráfica 8}

Margen de intermediación y tasa de inflación (1950-2001, \%)

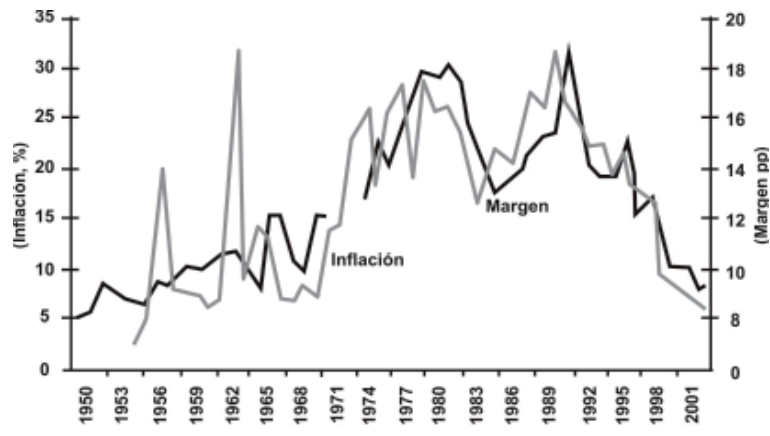

Fuente: ANIF.

\section{CRISIS FINANCIERAS NACIONALES}

En este apartado se analiza el papel de la intermediación financiera en el escenario de dos de las crisis de mayor impacto sobre la economía colombiana, presentadas durante las décadas de los 80 's y 90 's en Colombia; un factor común entre estas crisis, es el crecimiento económico que se vivía en el país, durante el periodo inmediato que antecede a cada una.

\section{Crisis de los ochenta}

\section{a) Antecedentes, causas y consecuencias}

A raíz de las heladas de los cafetales brasileños a mediados de 1975, el precio internacional del grano de café se disparó en 1976, situándose en un nivel de precio nunca antes visto; esto produjo un cambio significativo en diversos escenarios del mercado internacional del café, que encontró en la caficultura colombiana un mercado capaz de responder con el nivel de demanda externa que se generaba, por tanto, la producción y el nivel de exportaciones de café aumentó considerablemente, conduciendo a la economía hacia un escenario prospero, caracterizado por una bonanza de divisas, que se acrecentaba aún más por concepto del aumento en las exportaciones no tradicionales, las cuales se habían duplicado, y del aumento en las exportaciones de servicios; igualmente, a nivel internacional, crecía la liquidez, basada en una bonanza petrolera, que favoreció a los países latinoamericanos quienes gozaron de recursos de financiamiento a bajas tasas de interés. Pero en 1979, el precio del grano de café comenzó a bajar abruptamente, sellando así, el final de esta bonanza cafetera, que trajo como consecuencia la desaceleración del crecimiento económico nacional y el incremento desproporcionado de endeudamiento externo por parte de empresas, entidades del sistema financiero y sector público, quienes aprovechaban las oportunidades de crédito que ofrecía el mercado internacional.

Es así como emerge la crisis de los 80's, la cual estalla en el momento en que la Superintendencia Bancaria interviene a diferentes IFs, debido a un alto deterioro en sus carteras y a un alto nivel de endeudamiento externo; la cartera de los IFs se había expandido fuertemente como producto de la alta liquidez internacional, que les permitió obtener considerables recursos, que posteriormente trasladaron a las empresas nacionales, las cuales mostraban niveles satisfactorios de crecimiento económico en el momento; pero esta expansión del crédito no tuvo una adecuada evaluación del riesgo, lo que se tradujo posteriormente en un porcentaje significativo de cartera irrecuperable, ya que los prestatarios estaban sobreendeudados y la economía se desaceleraba.

La intervención de la Superintendencia se inició en 1982 con el Banco Nacional, el Banco del Estado y otros IFs que pertenecían al importante Grupo Financiero Correa, y cuatro años después, fueron también intervenidos el Banco Tequendama, el Banco de los Trabajadores, el Banco del Comercio y el Banco de Colombia. También paralelo a esta crisis, se presentó a nivel internacional, la denominada crisis de deuda externa de 1982, que acrecentó la decadencia del sistema financiero colombiano, aunque de forma moderada. 
Por otro lado, "La legislación vigente antes de 1982 era insuficiente, ya que una parte importante de las nuevas instituciones integrantes del sistema financiero y de las actividades ejercidas por los particulares no estaba sujeta a la regulación estatal. Por consiguiente el estado carecía de los instrumentos para vigilar e intervenir un numeroso conjunto de nuevas actividades que se hicieron presentes en la esfera financiera"26. Una inadecuada legislación es un factor negativo, ya que ante vacíos en las normas de control y supervisión, la actitud de los IFs frente a la moralidad financiera y la adecuada evaluación del riesgo desmejoran.

\section{Impacto de la crisis de deuda externa en la crisis de los 80's}

A comienzos de los 80's, los países industrializados comenzaron a implementar políticas restrictivas para controlar sus niveles de inflación, tal como el aumento de las tasas de interés, hecho que condujo a una disminución en los precios internacionales de los principales commodities, que a su vez impactó en una menor inversión por parte de los países exportadores de los mismos; también esta política involucró el redireccionamiento en el otorgamiento de créditos, los cuales se dirigieron en primera instancia a los países industrializados.

Las medidas adoptadas conllevaron, en 1982, a un cese del pago de los compromisos de deuda externa, por parte de México, debido a su incapacidad para financiarse dentro del mercado internacional, hecho que marcó el comienzo de la crisis de deuda externa por parte de los países latinoamericanos; caracterizada por graves problemas de liquidez, que llevaron a que algunos países refinanciaran sus deudas, en condiciones desventajosas.

En este escenario de crisis de deuda externa, Colombia disminuyó su nivel de reservas significativamente pasando de USD 5.600 millones en 1981 a tan solo USD 1.800 millones en 1984, diferencia que fue utilizada para cubrir sus pagos de servicio de la deuda; y además el sistema financiero, el sector público y el sector empresarial colombiano comenzaron a tener problemas

26 Moneda, Banca y Teoría Monetaria. Gaviria Cadavid Fernando. Colección Estudios de Economía. Sexta Edición. Univ. Jorge Tadeo Lozano. Pág. 107. para financiarse en el exterior, lo que agudizó la desaceleración de la economía, disminuyó los niveles de exportación y aumento el desempleo; aunque es importante recordar, como se mencionó anteriormente, que estos tres sectores registraban un considerable endeudamiento en el exterior durante los años anteriores a esta crisis de deuda externa, lo que tenía en alerta el nivel de riesgo de contraparte en las entidades prestadoras.

En general, esta crisis se caracterizó por altos niveles de endeudamiento empresarial, una débil legislación financiera y un alto deterioro de la cartera de los bancos, sumados a los problemas de liquidez derivados de la crisis de deuda externa internacional.

\section{b) La intermediación financiera en la crisis de los 80's}

Al finalizar la década de los setenta, la intermediación financiera registraba un auge extraordinario, pero el ritmo de la inflación, la restricción del crédito bancario, el desorden institucional, la desintermediación financiera y la expansión del mercado, que se registraba paralelamente, configuraba un escenario de crisis.

La desintermediación financiera implicó la canalización de recursos por fuera de las entidades financieras vigiladas por la Superintendencia Bancaria, y el surgimiento de innovaciones financieras que conllevaron a que algunas de las instituciones vigiladas implementaran mecanismos que no se ceñían con las reglamentaciones vigentes, realizados con el fin de eludir los controles.

Suscitada la crisis se implementó un grupo de medidas para atenuar el grave problema que afrontaban los IFs, tales como (1) la creación del Fondo de Garantías de Instituciones Financieras, cuyos fines primordiales radican en "la protección de los depositantes y acreedores de los IFs, preservando el equilibrio y la equidad económica e impidiendo injustificados beneficios económicos o de cualquier otra naturaleza de los accionistas o administradores causantes de perjuicios a las instituciones financieras", (2) la normatividad sobre la capitalización de las instituciones financieras, (3) las inyecciones de capital, y (4) la liquidación y estatización de entidades. 
En conclusión, en esta crisis se evidencia problemas de gestión del riesgo de contraparte, debido a que las entidades de crédito nacionales permitieron el crecimiento desproporcionado de endeudamiento de las empresas colombianas durante el periodo de 1978 a 1982, sin una adecuada medición del riesgo, que se refleja en los bajos niveles de reservas con los que contaban los IFs para cubrir las eventuales pérdidas que se generaron, lo que conllevó a una intervención sobre las mismas, por parte de las instituciones de control y supervisión; igualmente se identifican graves problemas de liquidez, derivados de la crisis de deuda externa, que limitó drásticamente las fuentes de financiamiento para el sistema financiero; también problemas de selección adversa en cuanto a la constitución de carteras de alto riesgo, seguidos de problemas de riesgo moral, en cuanto a inversiones por parte de las empresas en proyectos poco seguros y sin un correcto monitoreo por parte de los IFs; ambos hechos se materializaron con el incumplimiento del pago de las obligaciones financieras, registrándose un alto nivel de cartera irrecuperable en los IFs y quiebras de algunas empresas e IFs.

\section{Crisis de los Noventa}

\section{a) Antecedentes, causas y consecuencias}

A comienzos de la década de los noventa el país comenzaba a experimentar un nuevo rumbo económico-financiero, que generó un mayor nivel de confianza por parte de inversionistas tanto nacionales como extranjeros, ya que había bastante optimismo por la entrada en vigencia de la nueva Constitución de 1991, el descubrimiento de nuevos yacimientos petrolíferos, una caída significativa en los niveles de desempleo y la implementación de diversas reformas en temas: laborales, de pensiones, de inversión extranjera y de transformación de la estructura de los IFs; este último vislumbraba el fortalecimiento del sistema financiero, ya que distinguía las actividades propias de los diferentes IFs; todos estos hechos en conjunto se interpretaron como bases para un mayor nivel de riqueza que podía predominar en el futuro, pero tiempo después no se consolidó como se esperaba.

En 1994 se impulsó fuertemente la modernización del Estado y del sistema económicofinanciero, que involucraba, entre otros, es- tabilidad macroeconómica, eliminación en las distorsiones de precios, apertura tecnológica, apertura de capital competitivo, crecimiento de las exportaciones, flexibilización laboral y liberación financiera.

La liberación financiera incluida en esta nueva reforma, y materializada dentro de este escenario optimista, motivó al sistema financiero colombiano a aumentar su nivel de endeudamiento en el mercado internacional, e igualmente a colocar mayores recursos en forma de créditos a nivel nacional. Por otro lado, esta liberación financiera y una diferencia positiva entre la tasa de interés nacional y la internacional, hacían de Colombia una economía atractiva para invertir, caracterizada por un nivel de riesgo considerable pero poco volátil, dadas las condiciones enunciadas anteriormente.

Pero finalizando la década de los noventas, apareció la crisis, Colombia y las economías latinoamericanas fueron objeto de dos choques externos; el primero fue el deterioro de los términos de intercambio, como consecuencia de la crisis asiática de 1997, que produjo una drástica caída de los precios internacionales en los principales commodities; y el segundo fue la declaración de la moratoria de la deuda externa de Rusia durante 1998, evento que tomo por sorpresa al mundo financiero internacional y que generó el cambio abrupto en las expectativas de los inversionistas. Derivado de estos hechos, en Colombia, se registró una disminución del ingreso, producto de menores exportaciones, y a un menor precio, y una cuantiosa salida de capital extranjero, originado por la incertidumbre mundial.

Con este escenario, se encareció la deuda externa y se hizo más difícil conseguir recursos en el exterior, lo que disminuyó la liquidez en el sistema financiero, que además presentaba un excesivo nivel de cartera; igualmente las tasas de interés aumentaron y los prestatarios empezaron a incumplir sus compromisos de pago, lo que agravó la cartera de los bancos y obligó la intervención por parte del Gobierno, en la ejecución de planes de rescate o capitalización de IFs.

\section{b) La intermediación financiera en la crisis de los 90's \\ Implantadas las reformas del inicio de los años 90's, los IFs se caracterizaron por mejores niveles}


de competitividad, eficiencia y rentabilidad, derivados de la confianza de los agentes económicos hacia el sistema financiero. Además dentro del proyecto de internacionalización de la economía, que se adelantó durante esta década, los IFs jugaron un papel importante en su ejecución, lo cual incluía la alineación con estándares financieros internacionales, tales como los estipulados en Basilea.

Pero el creciente endeudamiento de los IFs, junto con la crisis asiática y la declaración de la moratoria rusa, condujeron a la crisis de los 90's; además se hizo visible un mayor grado de vulnerabilidad de la economía ante choques externos, producto de la liberación financiera suscitada, lo que exigió nuevos ajustes en la reforma financiera.

La actuación de las instituciones de control y supervisión en el manejo de la crisis de los años noventa, fue muy diferente de la crisis de los años ochenta. En esta crisis de los 90's, no solamente se suministró apoyo de liquidez a los IFs, sino que se apoyó la solvencia de la nación, a su vez el Banco de la República efectuó préstamos a empresas del sector productivo para mejorar su capital de trabajo, en particular, aquellas que pertenecían a los sectores con mayor dificultad financiera, golpeados por la crisis, tales como el textil, el siderúrgico y el de construcción, utilizando el mecanismo de redescuento y cobrando tasas de interés reales negativas.

Entre los tratamientos para superar esta crisis están, por ejemplo, los redescuentos otorgados por el Banco de la República para subsanar el problema de las deficiencias de liquidez, resultado de captaciones de corto plazo para otorgar préstamos de mayor plazo; y la capitalización de entidades, en los casos en que los desfases eran excesivos, de manera que lograran el índice de solvencia a los niveles establecidos por la Superintendencia Bancaria, aunque esta situación se presentó con pocos IFs.

En conclusión, en esta crisis se observó mayores problemas de gestión de riesgo, en comparación con la crisis de los 80's, derivados de la liberación financiera, la cual involucró un mayor número de variables en juego, dado el escenario internacional; igualmente faltó mayor responsabilidad con respecto al nivel de endeudamiento externo, por parte de los IFs, el cual fue exagerado; ambos hechos hicieron más vulnerable la economía, debido a que los IFs estaban más incentivados a tomar mayores riesgos, dadas las reformas financieras a favor de estos. Igualmente, esta mayor propensión al riesgo por parte de los IFs los condujo a problemas de selección adversa, por el afán de colocar los recursos que obtenían a bajas tasas de interés en el exterior, y paralelamente se incrementó el riesgo moral, producto del fácil acceso al crédito nacional por parte de los agentes, quienes invirtieron los recursos de los créditos en proyectos poco seguros; hechos que conllevaron al incremento de cartera de baja calidad, y posteriormente, a la intervención de las instituciones de control y supervisión.

\section{CONCLUSIONES}

La intermediación financiera se ha convertido en el eje central para el desarrollo y crecimiento económico de un país; por tanto, es de vital importancia que los IFs asuman con el mayor grado de responsabilidad el análisis de información en busca de sólidas señales que les permitan tomar decisiones confiables, la evaluación adecuada del riesgo con el fin de mitigar la materialización de las pérdidas, y el diseño de innovaciones financieras que conduzcan a una transparente evolución del sistema financiero.

La importancia del papel de la intermediación en las crisis financieras es absoluto, analizando los antecedentes, causas y consecuencias de la gran mayoría de las crisis citadas en este documento, se puede observar que muchas de ellas tienen en común, problemas de selección adversa y riesgo moral, más que el problema de duplicación de screening; aunque en muchas de estas crisis los principales responsables son los mismos IFs es difícil pensar en una economía sin IFs, sin regulaciones financieras, sin terceros agentes dentro de un intercambio que ofrezcan unas mínimas garantías sobre la calidad y custodia de los subyacentes; por el contrario, las evidencias de asimetría de información en las transacciones financieras aboga el papel de éstos en la creación de sistemas de información dinámicos, completos y profundos, y el diseño de estrategias de seguimiento sobre la actuación de los diferentes agentes económicos, con respecto al cumplimiento de sus obligaciones financieras. 
Por otro lado, es indispensable que los IFs aprendan a administrar los recursos en periodos de excesiva liquidez, donde aumenta la confianza y se disminuye el compromiso de evaluación de los riesgos, lo que hace más profunda una eventual crisis, tal como se ha visto en algunos de los casos analizados, ya que estos periodos de liquidez están generalmente basados en un excelente comportamiento atípico de precios, es decir, que no es permanente, sino que por el contrario, en la mayoría de los casos es solo transitorio.

Es claro, que un buen desempeño de la intermediación financiera, depende en cierta medida de las políticas monetarias y cambiarias que determine la Banca Central de cada nación, lo que genera cambios no solo en el sector financiero, sino también en el sector productivo, e indirectamente repercute en cada agente económico a través de las distintas operaciones financieras, tanto de inversión como de financiamiento; por tanto, estas medidas deben ser cuidadosamente estudiadas, ya que una exagerada legislación puede asfixiar a los IFs y volver lento el crecimiento de la economía, pero también, una débil legislación puede conducir al quebrantamiento de los compromisos, ilegalidad de las operaciones y bajo desempeño de los IFs, cuyas consecuencias podrían afectar a toda una sociedad, tal como ha sucedido en las diversas crisis financieras.

Por último, es importante también reflexionar sobre la dinámica de los sistemas financieros, la cual es cada vez más compleja y globalizada, permitiendo el desarrollo de innumerables innovaciones financieras, debido a la cantidad y diversidad de agentes económicos que desean participar en el mercado, e igualmente esta globalización facilita la expansión, de forma más rápida, tanto de soluciones como de problemas financieros que se pueden presentar en las distintas operaciones del mercado; dichas características han conducido a una economía mundial más volátil y más vulnerable ante los riesgos, que obliga a los IFs y Gobiernos, a trabajar en forma conjunta y con una rigurosa disciplina financiera, tanto en momentos de bonanza, propicios para ahorrar, como en momentos de crisis, donde se esperaría estar blindado.

\section{AGRADECIMIENTOS}

Los autores reconocen las contribuciones de Elisa Piedrahita Castillo con respecto al establecimiento de los criterios que guiaron la realización, en lo conceptual y contextual, de este documento, derivados de su intención de construir el Estado del Arte de la Ingeniería Financiera.

\section{REFERENCIAS BIBLIOGRÁFICAS}

Constanza Martínez Ventura. Ensayos sobre política económica. "Una revisión empírica sobre los determinantes en los márgenes de intermediación en Colombia, 1989-2003", Revista ESPE, No 48 Junio de 2005. Páginas 118-183.

[Stuart I. Greenbaum and Anjan V. Thakor. Contemporary Financial Intermediation. Academic Press Advanced Finance Series. Second Edition. 2007.

[Anthony M. Santomero. Una panorámica histórica a la teoría de la intermediación financiera. Papeles de Economía Española, ISSN 0210-9107, No 84-85, 2000 Paginas 2-16.

Franklin Allen and Anthony Santomero. The Theory of Financial Intermediation. The Wharton Financial Institutions Center. 1996.

Centro de estudios públicos de Argentina. Mario Teijeiro, http:// www.cep.org.ar o http://www.cep.org.ar

[N. F. Salazar. Represión financiera y márgenes de intermediación. Carta financiera ANIF № 131. Septiembre 2005.

N. F. Salazar. Evolución y determinantes del margen de intermediación en Colombia. Coyuntura económica / Fedesarrollo. Vol. 35. No 2. Segundo semestre 2005. Pág. 195-206.

A. Arias, A. Carrasquilla, A. Galindo. Efectos de la represión financiera. Documento CEDE 2002-02. ISSN 1657-5334. Abril de 2002.

V. C. Pérez, J. L. Lozano, G. L. Tam. Costo de la información en la intermediación financiera. UNMSM. Revista de la facultad de ciencias económicas.

P. B. Arciniegas. La estabilidad en las captaciones de los intermediarios financieros colombianos. Revista ESPE, No 6, Art. 04, Diciembre de 1984. Pág. 149-155.

J. A. Pérez. La gran depresión de 1930 en Colombia. Comercio Exterior Instituto Colombiano de Comercio Exterior INCOMEX (Bogotá). Vol. 12, No. 11 (noviembre 1980). p. 75.

P. Bustelo. Los orígenes de la crisis financiera de Argentina: una comparación con las crisis asiáticas. Boletín Económico de Información Comercial Española № 2715, 7-13 de enero de 2002, pp. 9-14.

P. Bustelo. Las crisis financieras asiáticas (1997-1999): nuevos indicadores y escasos precedentes. Boletín Económico de 
Información Comercial Española. N 2626, 6-12 de septiembre de 1999, pp. 21-25.

C. Caballero. Las crisis financieras del último cuarto del siglo XX. Revista coyuntura económica. 35 Años.

B.B. Aghevli. La crisis de Asia: causas y remedios. Finanzas \& desarrollo. Junio de 1999. Volumen 32, número 2.

R. R. Gutiérrez La crisis argentina del milenio. Una enseñanza para la política económica. Departamento de Economía. UNS. Agosto 2003.

S. Martínez, Senior IEEE, J.V. Miguez, Member IEEE y E. Rey. Plantilla de preparación de artículos técnicos en procesador de texto Word (Microsoft). Revista IEEE América Latina en español. 27 de Agosto 2007.

[¿Cómo llegamos a la crisis financiera global? Artículo que se encuentra en la página web: http://www.materiabiz.com/mbz/ economiayfinanzas.

L. Bleger. Asesor Económico Financiero-Adscripto a Presidencia Argentina. La etapa actual de la globalización financiera: La crisis de las hipotecas en EE.UU y su impacto mundial. http:// www.unsam.edu.ar/escuelas/politica/ideas.

Unidad editorial internet S.L Elmundo.es. El Crash del 2008. http://www.elmundo.es/especiales/2008/10/economia/crisis2008/

Luis Ángel Rojo. Políticas, Mercados instituciones económicas. Estudios en homenaje a Luis Ángel Rojo. Volumen 1.

G. Bernard. Barcelona. La crisis de 1929. Oikos-Tau, 1985. $148 \mathrm{p}$.

Salomon Kalmanovitz K., Mauricio Avella G. Barreras del desarrollo financiero: las instituciones monetarias colombianas en la década de 1950. Septiembre de 1998.

Claudia Tafur Saiden. Bancarización: una aproximación al caso colombiano a la luz de América latina. 2009.

M. A. Arbeláez, S. Zuluaga. Impuestos implícitos y explícitos al sector financiero colombiano: 1995-2001.

A. J. López. Análisis de la relación entre intermediación crediticia y crecimiento económico en Venezuela. Banco Central de Venezuela. Julio 2003.

D. Ampuero. Crisis bancaria: causas y posibles soluciones. Instituto ecuatoriano de economía política. Evolución y cambio. № 13. 2005.

Intermediación financiera, financiación de préstamos con recursos propios. Superintendencia financiera. Concepto 2008033390-001 del 4 de junio de 2008.

Decreto 1981 de 1988. Septiembre 26. Diario oficial No 38.514, 28 de septiembre de 1988. Por el cual se reglamenta el decreto 2920 de 1982.

La Ley Bancaria del 16 de Junio de 1933. Estados Unidos.
Claudio González Iturriaga. Conferencia denominada: Análisis de la Crisis Financiera Mundial derivada de las Hipotecas Subprime. Memorias del II Seminario Internacional Mercados Competitivos. Programa de Ingeniería Financiera UPC. 2008.

Gabriel Holand. Curso de Riesgos y Derivados Financieros. II Seminario Internacional Mercados Competitivos Argentina. Programa de Ingeniería Financiera UPC. 2008.

Carrasquilla y Zarate. EI Sector Financiero de Cara al Siglo XXI. Bogotá. ANIF 2002. Páginas: 215-230. Volumen 1.

Moneda, Banca y Teoría Monetaria. Gaviria Cadavid Fernando. Colección Estudios de Economía. Sexta Edición. Univ. Jorge Tadeo Lozano.

Ley "Plan de Convertibilidad". Argentina.

Ley de Intangibilidad de los Depósitos. Argentina. Septiembre 2001.

Ley para la creación del Fondo de Garantías de Instituciones Financieras. Colombia.

Leonardo Villar, David Salamanca, y Andrés Murcia. Crédito, Represión Financiera y Flujo de Capitales en Colombia. 19742003.

Andrés F. Arias. The Colombian Banking Crisis: Macroeconomic, Consequences and What to Expect. August 2000.

Serge Jeanneau y Camilo E. Tovar. Implicaciones de los mercados de bonos en moneda local para la estabilidad financiera. Un resumen de los riesgos. BIS paper № 36 . 